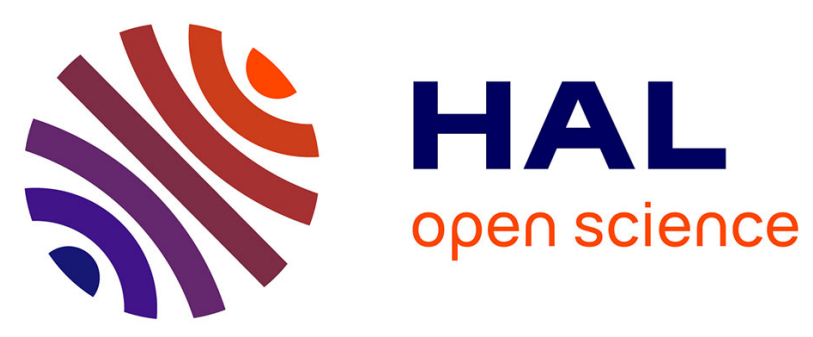

\title{
Magnetic and magnetorheological properties of nanofiber suspensions
}

Ana Gomez-Ramirez, Modesto Lopez-Lopez, Pavel Kuzhir, Juan D. G. Durán, Fernando Gonzalez Caballero

\section{To cite this version:}

Ana Gomez-Ramirez, Modesto Lopez-Lopez, Pavel Kuzhir, Juan D. G. Durán, Fernando Gonzalez Caballero. Magnetic and magnetorheological properties of nanofiber suspensions. 12th international conference on electrorheological fluids and magnetorheological suspensions, Aug 2010, Philadelphia, United States. hal-00857136

\section{HAL Id: hal-00857136 https://hal.science/hal-00857136}

Submitted on 2 Sep 2013

HAL is a multi-disciplinary open access archive for the deposit and dissemination of scientific research documents, whether they are published or not. The documents may come from teaching and research institutions in France or abroad, or from public or private research centers.
L'archive ouverte pluridisciplinaire HAL, est destinée au dépôt et à la diffusion de documents scientifiques de niveau recherche, publiés ou non, émanant des établissements d'enseignement et de recherche français ou étrangers, des laboratoires publics ou privés. 


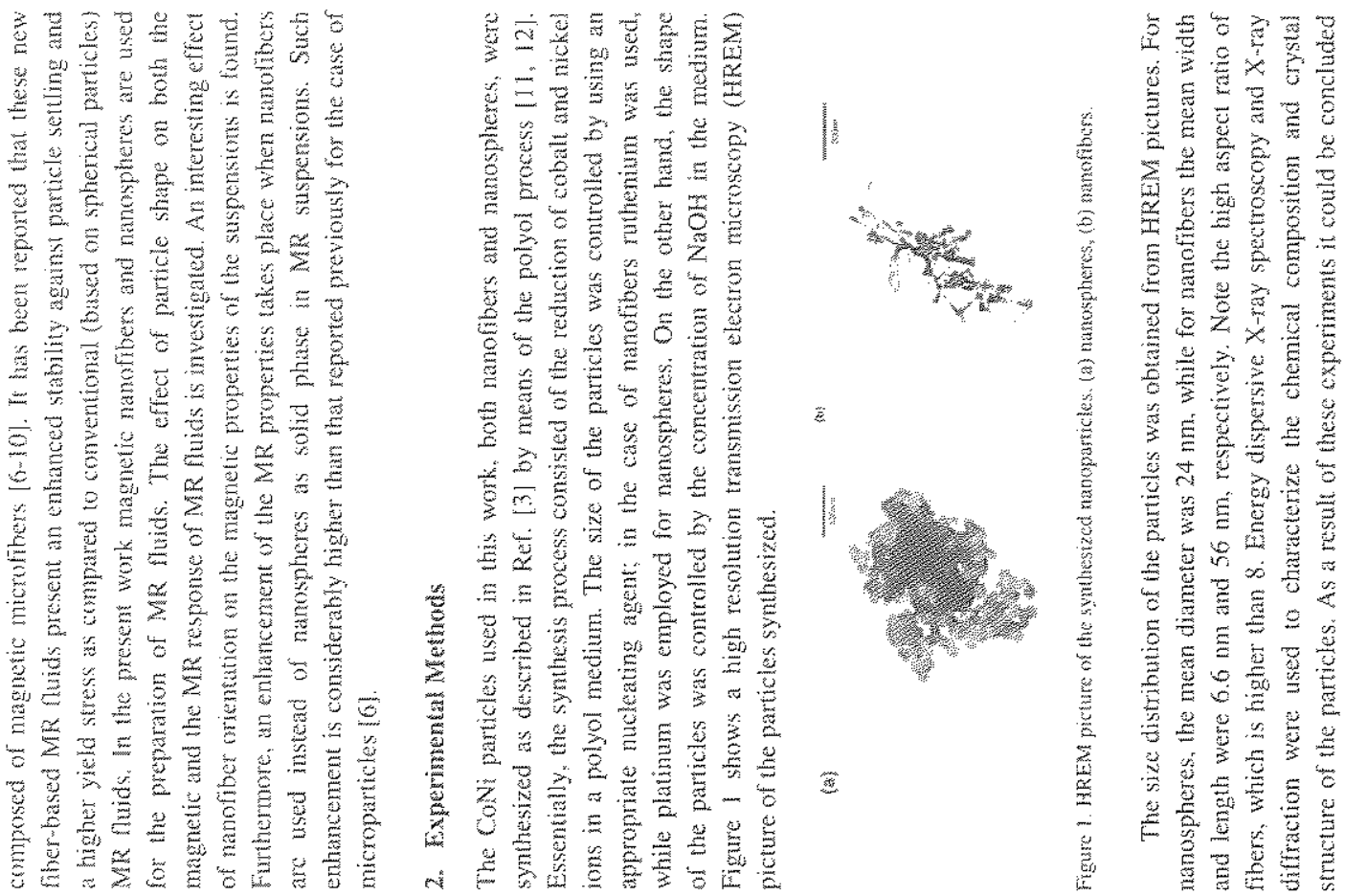
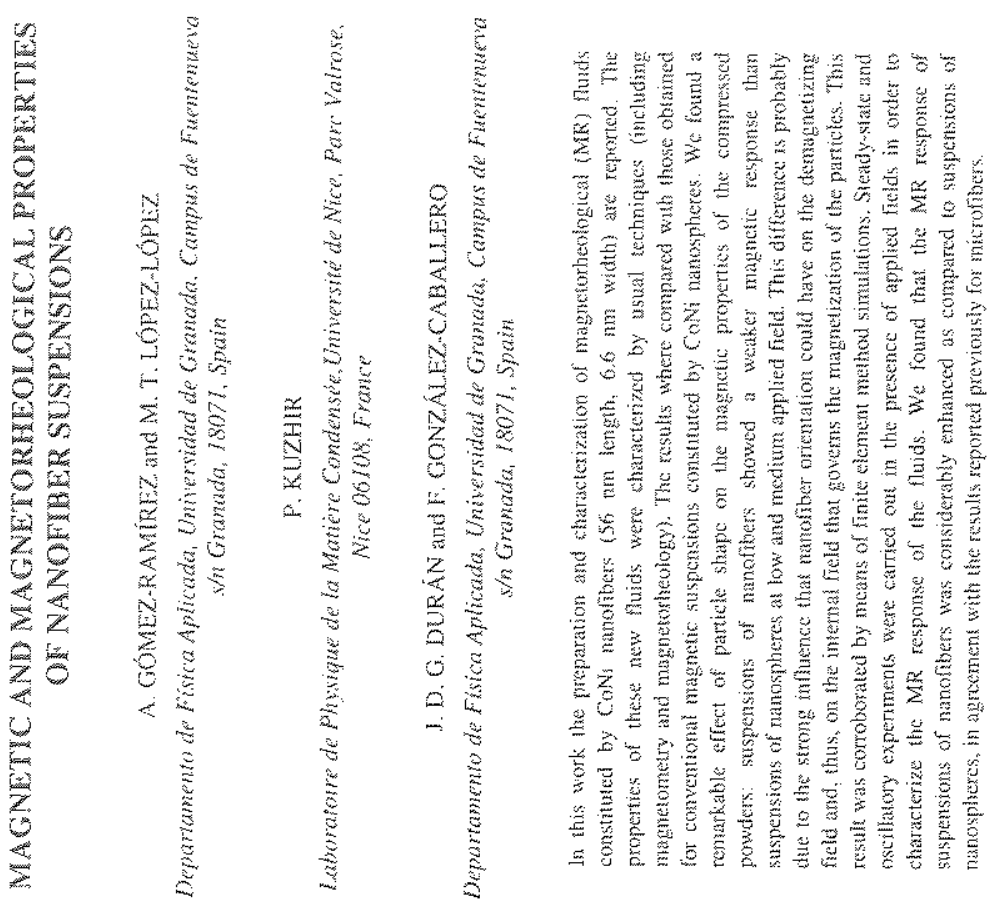

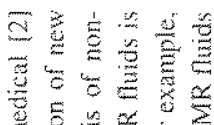

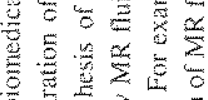

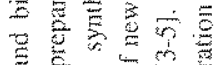

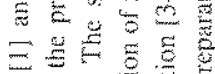

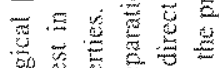

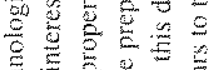

焉焉焉

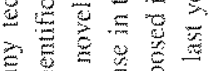

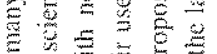

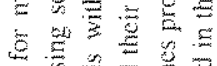

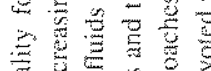

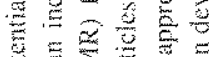

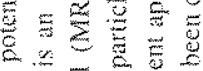

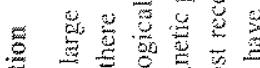

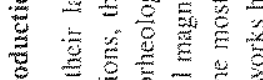

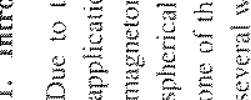




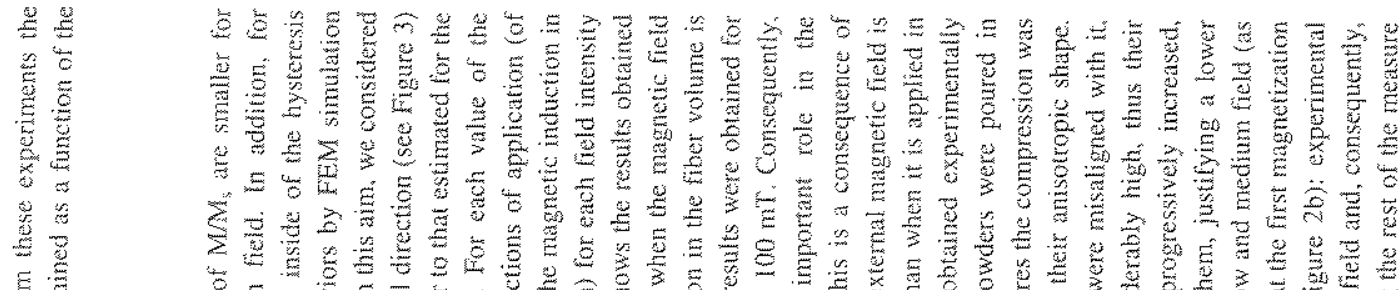

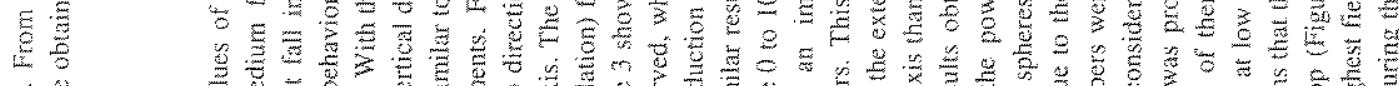

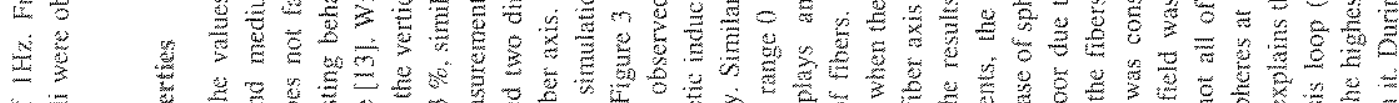

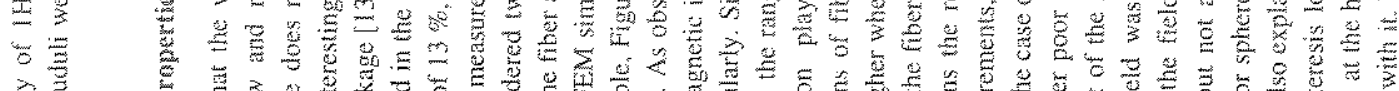

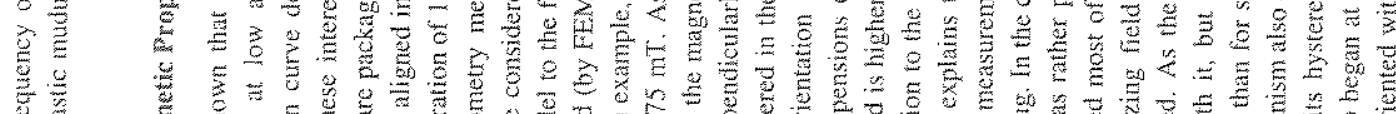

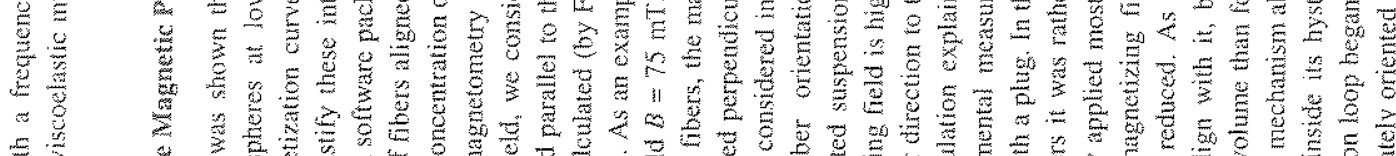

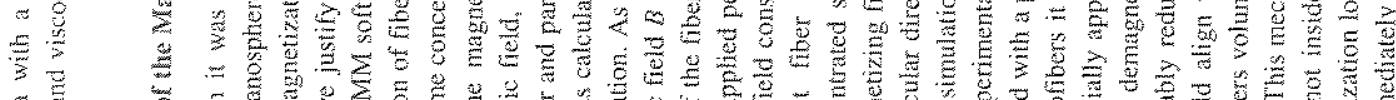

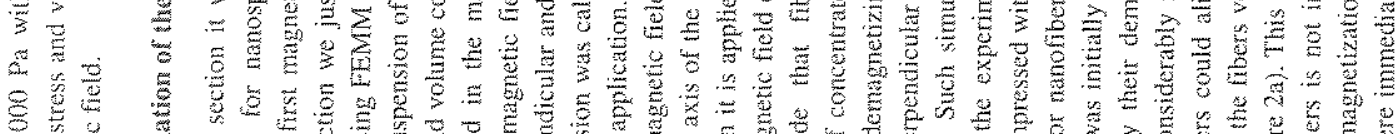

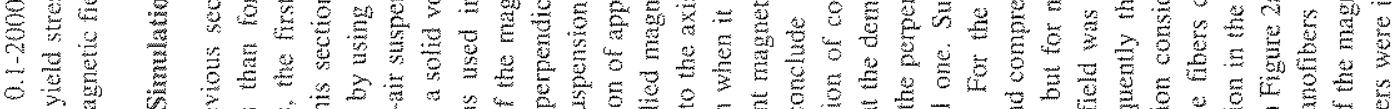

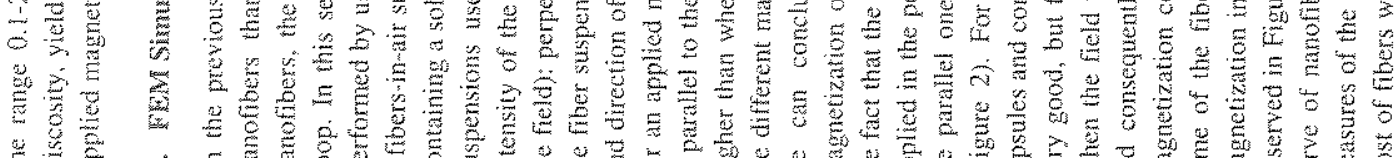

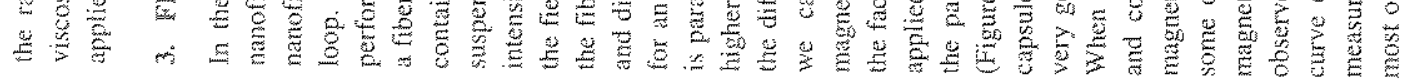

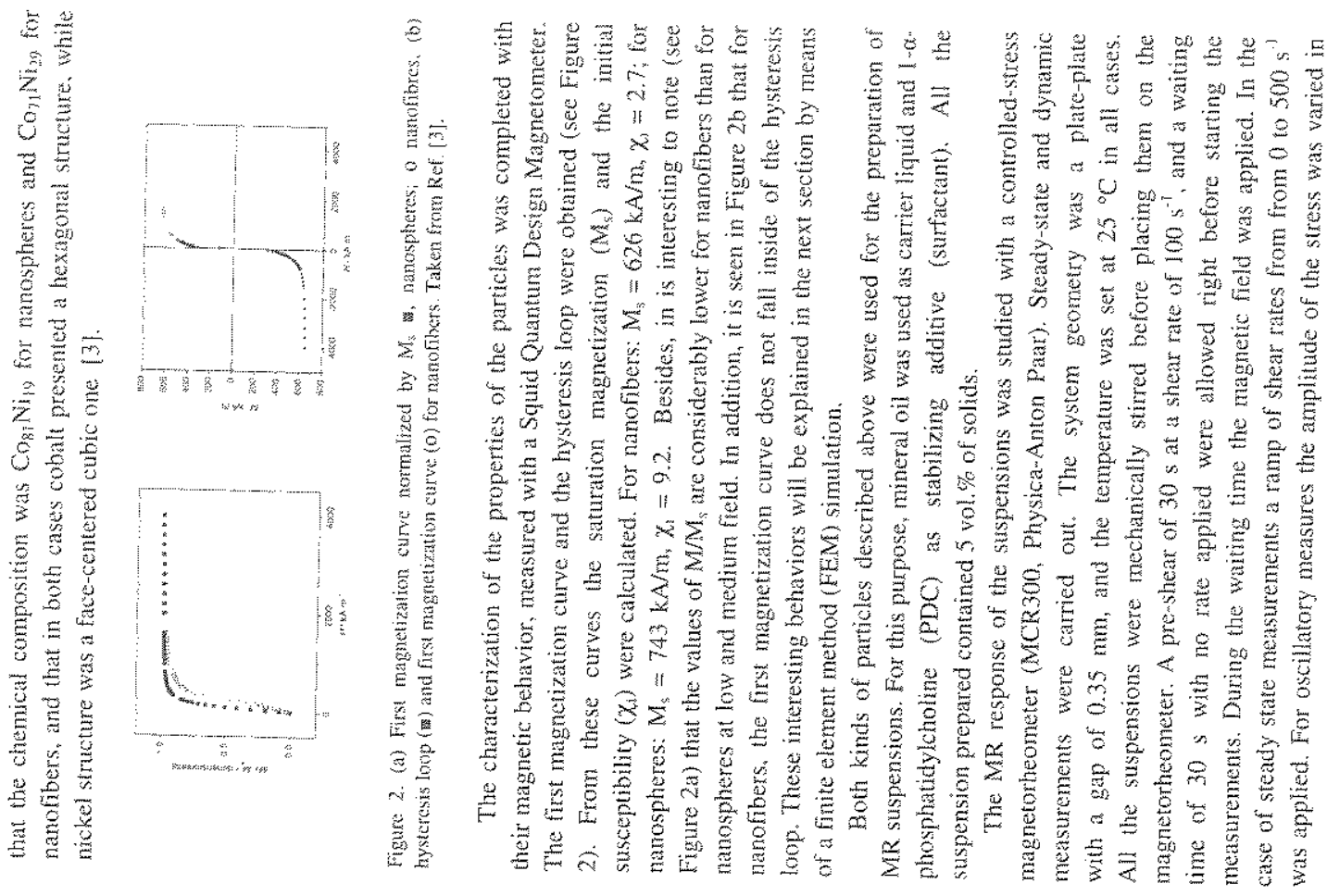




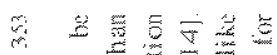

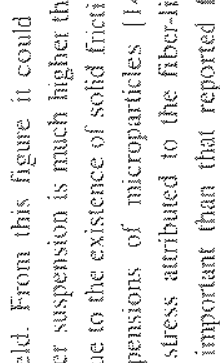

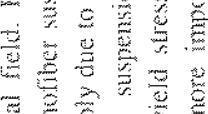

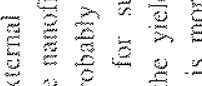

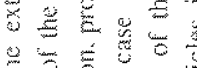

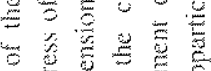

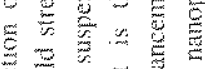

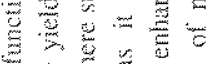

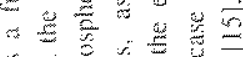

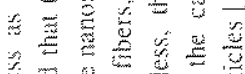

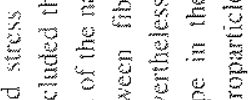

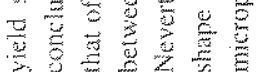

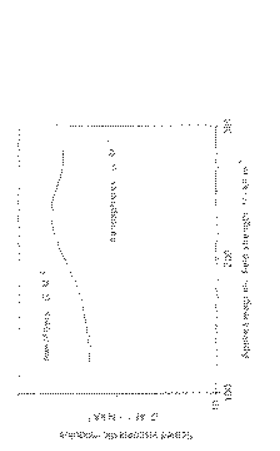

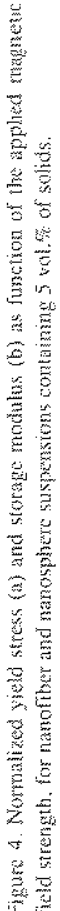

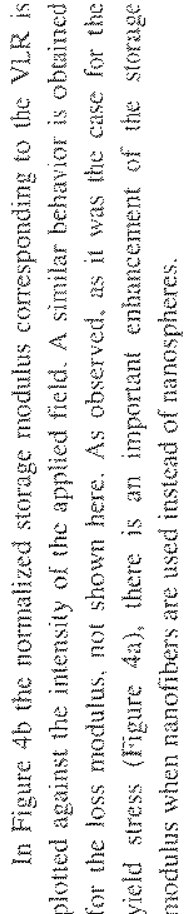

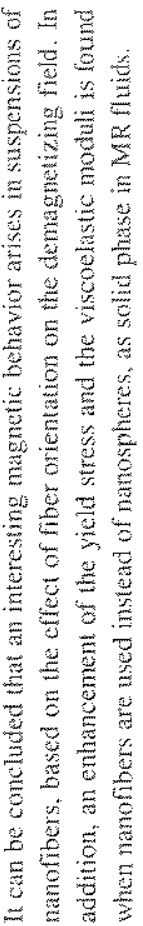

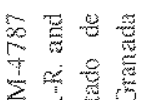

谣的

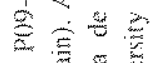

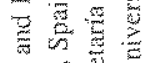

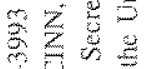

运尚

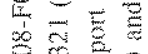

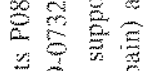

爱

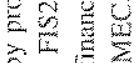

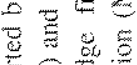

言衰䇏器

s.

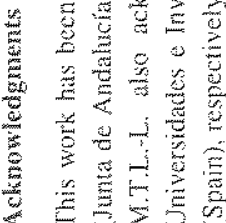

$\stackrel{\mathscr{E}}{\mathrm{E}}$

跣

要

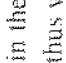

马ु

焉

范芯

를

点芯

管

$\stackrel{0}{2}$

믈

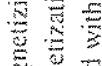

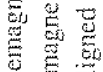

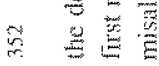

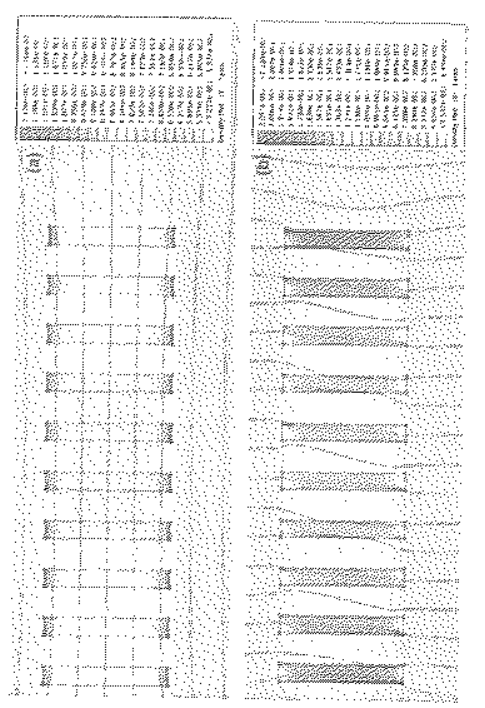

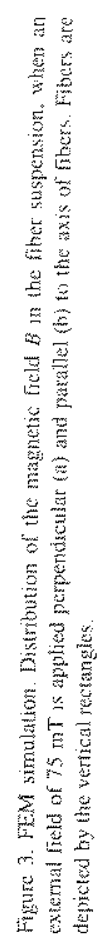

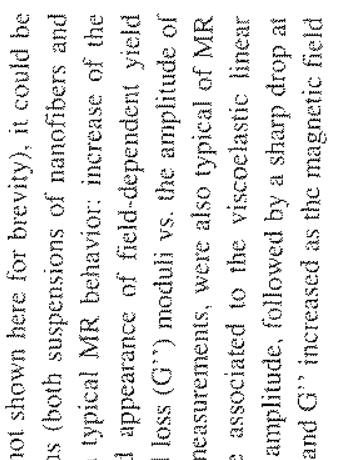

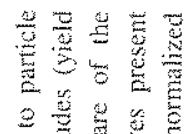

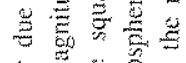

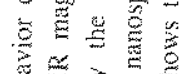

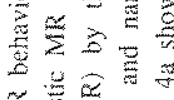

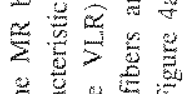

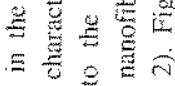

焉

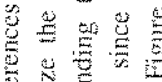

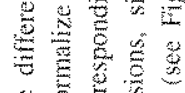

ङ气 50

है

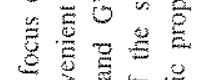

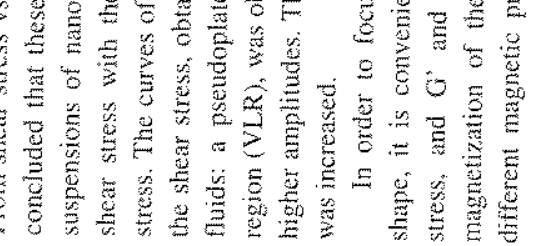

